\title{
EXCITON TRANSPORT IN NAPHTHALENE ALLOYS: A TRANSITION FROM PERCOLATION TO DIFFUSION ${ }^{+}$
}

\author{
S T GENTRY and R. KOPELMAN \\ Department of Chemustry. The Unuerstry of Micingan, Ann Arbor, Michigan 48109, USA
}

Recived 9 August 1982

Steady-state singlet excitation transport in ternary naphthalene crystals $\left(C_{10}{ }_{B} / C_{10} D_{8} / \beta\right.$-methylnaphthalene) fits diffusion modcls at $4.2 \mathrm{~K}$, but not at $18 \mathrm{~K}$, where it fits a percolation model

Simple diffusion models have repeatedly been suggested for the "critical" electronic energy transport in substitu tonully disordered binary crystals [1-3]. Our old naphthalene steady-state singlet data [4], have been fitted to such models with apparent success [2,3] We have recently pointed out [5] that our low-temperature tinie-evolution studies do not fit homogeneous diffusion models. but do fit heterogeneous cluster kinetics We show liere that our new steady-state data can be fitted by diffusion models at $42 \mathrm{~K}$ but not at $18 \mathrm{~K}$. This agrees with our recent theoretıcal studies on the quantuni-mechanical basis for the clusterization of exciton states and the resulting percolatuve transport [6-8].

Experimentally, the sample composition was much belter controlled than in previous work $[4,9]$. Also the evaluation of the relative intensities of the supertrap and the guest fluorescence was much refined, especially concernung the phonon side-band contributions (see fig. 1). Detaus, as well as a complete description of the experimental procedures, are given elsewhere [10] The eiperinentally determined observable

$P=I_{\mathrm{s}} /\left(I_{\mathrm{s}}+2 I_{\mathrm{g}}\right)$,

where $I_{\mathrm{s}}$ is supertrap emission and $I_{\mathrm{g}}$ guest emission, is plotted against the guest concentration (fig. 2), normalized with respect to the critical concentration $C_{1 / 2}$ (the value of the latter is $0.75 \mathrm{~mol}$ fraction for $1.8 \mathrm{~K}$ and 0.63 for $4.2 \mathrm{~K}$ ).

\footnotetext{
${ }^{+}$Supported by NSF Grant DMR 8000679.
}

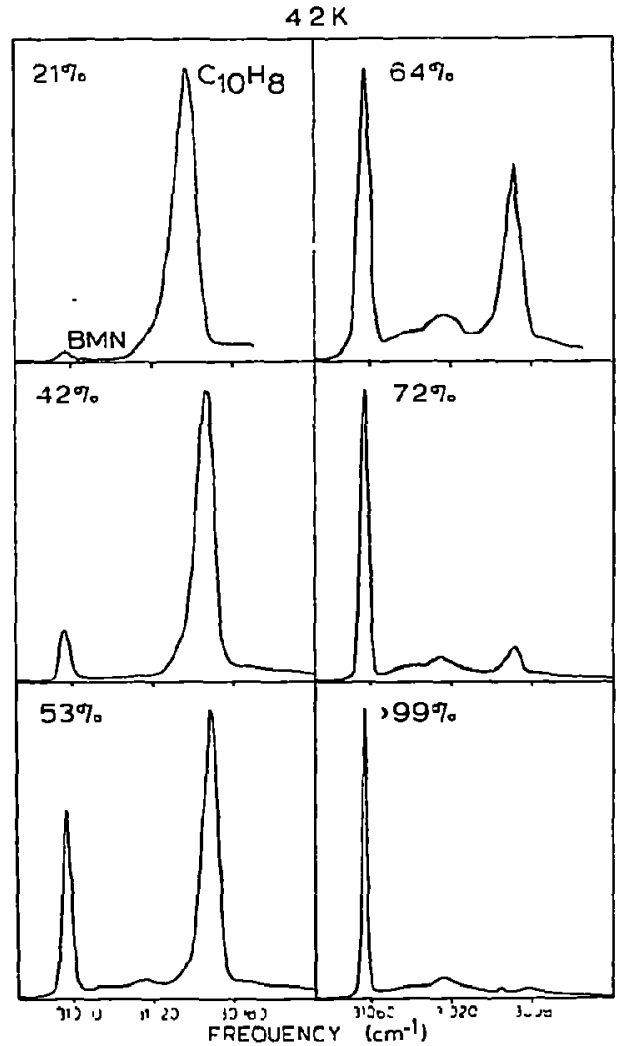

rig. 1. Guest and supertrap fluorescence spectra for the ternary crystal system $\mathrm{C}_{10} \mathrm{D}_{8} / \mathrm{C}_{10} \mathrm{H}_{8} / \mathrm{BMN}$. The guest concentration was varied whule mauntaining a constant supcrtrap. guest concentration ratio of $10^{-3}$. This set oi spectra was recorded at a temperature of $4.2 \mathrm{~K}$. The BMN 0-0 zero-phonon peak is located at $31061 \mathrm{~cm}^{-1}$ for a $100 \% \mathrm{C}_{10} \mathrm{H}_{8} / \mathrm{BMN}$ crystal 


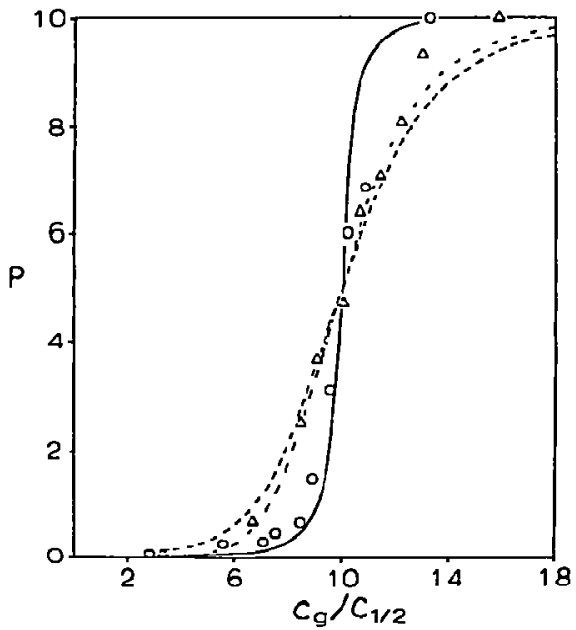

$\Gamma$ ig 2 Trapping probability versus reduced concentration $C_{1 / 2}$ is defined as the concentration correspondeng to $P=05$. Experumental cercles are $18 \mathrm{~K}$ data, tnangles are $42 \mathrm{~K}$ data. Theoretucal: the solid and dashed lunes correspond to percolation and the Loring and $\Gamma$ yyer calculation respectively, the dot-dashed line was calculated using the Blumen and Subcy model. The Blumen and Silbey and the Loring and Tayer curves assume octupole-octupole transfer withen a two-dmensional contınuum. The experimental data and the percolation and Blumen and Silbey curves are all with $C_{\mathrm{s}} / C_{\mathrm{g}}$. 0.001 . The Loring and Fuyer curve kept $C_{\mathrm{s}}$ constant at $C_{\mathrm{s}}=$ 0001 . Changing the Loring and $\Gamma$ ayer curve to account for a constant $C_{\mathrm{s}} / C_{\mathrm{g}}$ ratio would only add a small correction As a comparison, if the Blumen and Silbey equations were calculated using $C_{\mathrm{s}}=0.001$ then the result would lie half way between the dot-dashed and the dashed lines for $C_{\mathrm{n}} / C_{1 / 2}<10$, for $C_{\mathrm{g}} / C_{1 / 2}>1.0$ the result is essent ially identical to the Lorung and rayer curves.

Fig. 2, in addition, compares the experimental $p$ (for $C_{\mathrm{g}} / C_{\mathrm{g}}=10^{-3}$ ) with the diffusion and percolation models. The percolation results were based on Monte Carlo simulations [11] on a $400 \times 400$ square lattice with NN interactions and a constant $C_{\mathrm{s}} / C_{\mathrm{g}}=10^{-3}$. The Loring and Fayer and the Blumen and Silbey curves are based on octupole-octupole transfer in a two-dımensional contunuum. The Blumen and Silbey curve is for $C_{\mathrm{s}} / C_{\mathrm{g}}=10^{-3}$. The Loring and Fayer result is based on $C_{\mathrm{s}}=10^{-3}$ and with the adjustable parameter set at $R_{0}=8 \AA$. The Blumen and Silbey result for $C_{\mathrm{S}}=10^{-3}$, however, would be identical to that of Loring and Fayer for $C_{\mathrm{g}}>C_{1 / 2}$, and twice as close as shown in fig. 2 to the Loing and Fayer curve for $C_{\mathrm{g}}<C_{1 / 2}$ The upshot from this is that the two diffusion models give identical results, withın our ex- perimental uncertainties However, the difference between the diffusion and percolation model is signif!cant, especially in the vicenity of the critical threshold

The diffusion models obviously ignore the clusterzzation of guest sites and the conconitant energy nus. matches (of cluster states), as they assume the high temperature limit för guest-guest transfer. At low temperature, however, forward and backward transfers can be very different, especially for longer-range "hops". In addition, the random hopping idea (based on localized states) is more suspect at lower temperatures Even at $4.2 \mathrm{~K}$, where the diffusion model does fit the data, 11 slivuld not be taken too literally. The fitting paraneter $\left(R_{0}=8 \AA\right)$, with a NN distance of $5 \perp \AA$ and a lifetimic of 120 ns, gives a nearest-neighbor transfer tume of $200 \mathrm{ps}$, while the usual estumate [12] is $\approx 1$ ps The slow transfer rate may be a manifestation of an effective averagung over slow back-transfer between energy-musmutched clusters, etc.

The fit to the percolation model excludes the supertransfer case [11] and lias to be based on models where transport inside the supercluster is not infintely fast but rather incfficient duc to the ramlfied topology This has becn shown before $[11,13]$ both experimentally and via sumulations. where the simulations included a quast-coherent ("correlated walk") description of the exciton motion inside the disordered guest lattice $A$ rough fit would be achieved with a correlation value $[13 \mid$ of $I \geq 10,1 \mathrm{c}$ one scattering event per ten or more transfers

In summary, our more refined experımental data allow us to critically test current models of energy transfer in disordered media The generalized diffusion models of GAF [3] and of Blumen and Silbey do fit the $4.2 \mathrm{~K}$ data, even though the resulting interaction parameter may be physically unrealistic. They do nut fit the $18 \mathrm{~K}$ data. The better fit of the percolation model at $1.8 \mathrm{~K}$ is reasonable on two physical counts The longer-range transfers are very inefficient at $18 \mathrm{~K}$ in view of the cluster energy mismatches, and can thus be effectively ignored or "cut-of $\Gamma$ ". The slor test-range transfers at $1.8 \mathrm{~K}$ are quasi-colierent, resulting in a sharp rise in transport efficiency as the nearest-neighbor infinite cluster topology changes from effectively one-dımensional ("ranufied") to twodimensional. 
We thank R.F. Lorng and M D Fayer for a preprint of their work and several private communicathons We would also like to thank A. Blumen and R. Parson for frutful discussions.

\section{References}

III I Klufter and J. Jortner, Chem. Phys Letters 60 (1978) 5.

[2] A. Blumen and R. Silbcy, J. Chem. Phys 70 (1979) 3707.

[3] R F. Lonng and M D Fayer, Chem. Phys 70 (1982) 139;

R.I. Lorung, H.C. Andersen and M D Fayer, 1. Chem Plus 76 (1982) 2015.

C.R Gouchanor. H C. Andersen and M D Fayer, J Chem Phys. 70 (1979) 4254

[1] R. Kopelman, E.M. Monborg. F.W Oclis and P. Prasad. Phys. Rev Letters 34 (1975) 1506
[5] R.P. Parson and R. Kopelman, Chem. Phys. Letters 87 (1982) 528.

[6] $R$ Kopeiman, in. Modern problems in solid state physics, eds V.M. Agranovich and R.M. Hochstrasser (North-Holland, Amsterdam), to be publushed.

[7] R. Parson and R. Kopelman, unpublished.

[8] R. Kopelman and P. Argyrak 1s, J. Chem. Phys 72 (1980) 3053

[9] R. Kopelman, C.M. Monberg and F.W Ochs, Chem Pliys. 21 (1977) 373.

[10] S.T. Gentry and R. Kopelman, unpublushed

[11] R. Kopelman, in 'Topics in applied physics, Vol. 15, ed. F.K. Fong (Springer, Berlin, 1976) p. 297; I Newhouse, 3 Hoshen and R Kopelman, unpublushed.

[12] M. Kohler, D. Schmid and H.C. Wolf, J. Luminescence 14 (1976) 41;

A. Propstl and H.C. Wolf, Z. Naturforsch. 18a (1963) 822, R.C Powell and 2.G. Soos, J Luminescence 11 (1975) 1.

[13] P. Argyrakis and R. Kopelman, Chem. Phys. 57 (1981) 135. 